\title{
COLANGIOCARCINOMA EM CÃO COM METÁSTASE EM OMENTO, LINFONODOS REGIONAIS E PÂNCREAS - RELATO DE CASO
}

Marco Aurélio Gusmão ${ }^{1}$ Daniel Keller

Almir Alves dos Santos Filho

Márcia Bersane Araújo de Medeiros Torres ${ }^{3}$

GUSMÃO, M. A.; KELLER, D.; SANTOS FILHO, A. A. dos; TORRES, M. B. A. de M. Colangiocarcinoma em cão com metástase em omento, linfonodos regionais e pâncreas - relato de caso. Arq. Ciênc. Vet. Zool. UNIPAR, Umuarama, v. 18, n. 2, p. 129-132, abr./jun. 2015.

RESUMO: Os colangiocarcinomas são neoplasmas malignos originados de ductos biliares ou da vesícula biliar que apresentam como principal diagnóstico diferencial os hepatocarcinomas com padrão acinar. Relata-se aqui um caso de colangiocarcinoma de ductos biliares em um cão com metástase em omento, linfonodos regionais e pâncreas, diagnosticado no Laboratório de Patologia Veterinária da UFPR - Setor Palotina.

PALAVRAS-CHAVE: Neoplasia hepática. Fígado. Carnívoros

\section{CHOLANGIOCARCINOMA IN DOG WITH METASTATIC OMENTUM, REGIONAL LYMPH NODES AND PANCREAS - CASE REPORT}

\begin{abstract}
Cholangiocarcinomas are malign neoplasms originated from bile ducts or from the gallbladder that present hepatocellular carcinomas with acinar pattern as the main differential diagnostic. This work has the objective of describing a case of cholangiocarcinoma of the bile ducts in a dog with metastasis in omentum, regional lymph nodes and pancreas, diagnosed at the Veterinary Pathology Laboratory of UFPR - Setor Palotina.

KEYWORDS: Hepatic neoplasms. Liver. Carnivores.

\section{COLANGIOCARCINOMA EN PERRO CON METÁSTASIS EN EPIPLÓN, GANGLIOS LINFÁTICOS REGIONALES Y PÁNCREAS - RELATO DE CASO}

RESUMEN: Los colangiocarcinomas son neoplasmas malignos originados de vías biliares o de la vesícula biliar que presentan como principal diagnóstico diferencial los hepatocarcinomas con estándar acinar. Se describe un caso de colangiocarcinoma de vías biliares en un perro con metástasis en el epiplón, nódulos linfáticos regionales y páncreas, diagnosticado en el Laboratorio de Patología Veterinaria de la UFPR - Sector de Palotina.

PALABRAS CLAVE: Neoplasia hepática. Hígado. Carnívoros.

Introdução

Os colangiocarcinomas ou carcinomas de ductos biliares são neoplasmas malignos originados principalmente dos ductos intra-hepáticos, e também dos ductos extra-hepáticos ou da vesícula biliar (CULLEN; POPP, 2002). Esses neoplasmas são descritos em cães, gatos, ovinos, bovinos, equinos e cabras (CULLEN; POPP, 2002), mas ocorrem principalmente em cães e gatos idosos (KELLY, 1993).

Os colangiocarcinomas não têm uma causa reconhecida em animais domésticos, porém existem alguns fatores de risco associados ao seu aparecimento, havendo maior incidência em cadelas castradas em relação à fêmeas intactas ou machos (CULLEN; POPP, 2002). Os principais fatores de risco são parasitas que causam lesões crônicas no sistema biliar como o Platynosomun concinum (ECHETO et al., 2005), agentes químicos, como plutônio e nitrosaminas (CULLEN; POPP, 2002; TAYLOR et al., 1991), parasitas intestinais como Ancylostoma sp. e Trichuris vulpis e inflamações crô- nicas independentes da etiologia que provoquem aumento da proliferação das células epiteliais dos ductos biliares (CULLEN; POPP, 2002).

Os sinais clínicos do colangiocarcinoma são inespecíficos e similares para cães e gatos. Sinais como letargia, anorexia, vômito, perda de peso e dispnéia são mais frequentemente relatados neste neoplasma e no carcinoma hepatocelular. A elevação do nível sérico das enzimas alanina transaminase (ALT) e aspartato transaminase (AST) é um achado bioquímico também compartilhado entre essas duas neoplasmas. No caso das neoplasias de ductos, 10 a 40\% dos cães e gatos podem apresentar sinal clínico de icterícia (PATNAIK, 1981).

Os neoplasmas hepáticos podem ser visualizados por ultra-sonografia e o diagnóstico pode ser realizado por biópsia percutânea por agulha fina (BONFANTI et al., 2004; MISCHKE et al., 2003). De acordo com Patnaik (1981) no caso dos colangiocarcinomas há uma tendência de se visualizar um padrão multifocal, já os carcinomas hepatocelulares

DOI: https://doi.org/10.25110/arqvet.v18i2.2015.5384

${ }^{1}$ Graduados em Medicina Veterinária. Universidade Federal do Paraná, UFPR, Brasil. e-mail: marco gusmao@hotmail.com

${ }^{2}$ Graduando em Medicina Veterinaria. Universidade Federal de Pernambuco - Campus Garanhuns, UFRPE, Brasil. e-mail: almiralves_eu@hotmail.com;

${ }^{3}$ Doutora em Patologia, Professora Adjunta de Patologia Veterinária, Laboratório de Anatomia e Patologia Animal da Unidade Acadêmica de Garanhuns UFRPE. Av. Bom Pastor, S/N, Boa Vista, Garanhuns, PE, 55.296-901. e-mail bersane@hotmail.com (autor para correspondência). 
tendem a possuir um padrão focal, auxiliando na diferenciação. A citologia tem utilidade limitada no diagnóstico de carcinoma hepatocelular bem diferenciado, uma vez que os hepatócitos podem lembrar a aparência normal de hepatócitos, de adenoma hepatocelular ou de hiperplasia nodular (CULLEN; POPP, 2002).

Macroscopicamente, o neoplasma apresenta-se como massa grande solitária ou múltiplos nódulos firmes, elevados, frequentemente com uma depressão, de coloração cinza- pálido ou bronzeados e não encapsulados. Microscopicamente, os neoplasmas consistem de dúctulos ou ácinos rudimentares de epitélio biliar separados por estroma de tecido conjuntivo fibroso. Esta neoplasia causa metástases principalmente para os linfonodos regionais, pulmões e cavidade peritoneal (MACLACHLAN; CULLEN, 1998). As vias de disseminação do neoplasma para outros órgãos são linfática, hematógena, em menor grau, ou implantação no peritônio (KELLY, 1993).

O objetivo desse trabalho foi relatar um caso de colangiocarcinoma em um cão, com metástase em omento, linfonodos regionais e pâncreas, diagnosticado no Laboratório de Patologia Veterinária da Universidade Federal do Paraná (UFPR) - Setor Palotina.

\section{Relato de Caso}

Um cão, macho, sem raça definida, um ano e nove meses foi atendido no Hospital Veterinário da UFPR, Campus Palotina, no ano de 2008, apresentando hiporexia, apatia, desidratação, mucosas aparentes pálidas e com histórico de insuficiência hepática. Aumento das enzimas hepáticas AST e ALT, 133,27 (U/1) e 137,80 (U/1) respectivamente, quando os valores de referência para cães são de 26 a 66 (U/l) para AST e 21 a 102 (U/1) para ALT. (KANEKO, 1989). O animal morreu e foi realizada a necropsia no Laboratório de Patologia Veterinária da UFPR - Setor Palotina.

$\mathrm{Na}$ necropsia o animal apresentava icterícia nas mucosas aparentes durante o exame externo, bem como em todo tecido subcutâneo e aproximadamente $130 \mathrm{~mL}$ de líquido sanguinolento na cavidade abdominal foi retirado. Apresentava também hepatomegalia e fígado com nódulos branco-amarelados na superfície variando de 1,0 a $15,0 \mathrm{~cm}$ de diâmetro, multifocais, de consistência firme e aspecto umbilicado, que se aprofundavam ao corte (Figura 1). Os linfonodos hepáticos e pancreáticos estavam aumentados de volume e no omento havia nódulos multifocais branco-amarelados, firmes, medindo de 0,5 a 1,5 cm de diâmetro (Figura 2). No pâncreas havia vasos dilatados com trombos aderidos à parede.
Figura 1: Fígado com hepatomegalia e nódulos neoplásicos mais claros multifocais de um cão macho, sem raça definida (SRD), submetido à necropsia no Laboratório Patologia do Hospital Veterinário da UFPR - Setor Palotina.

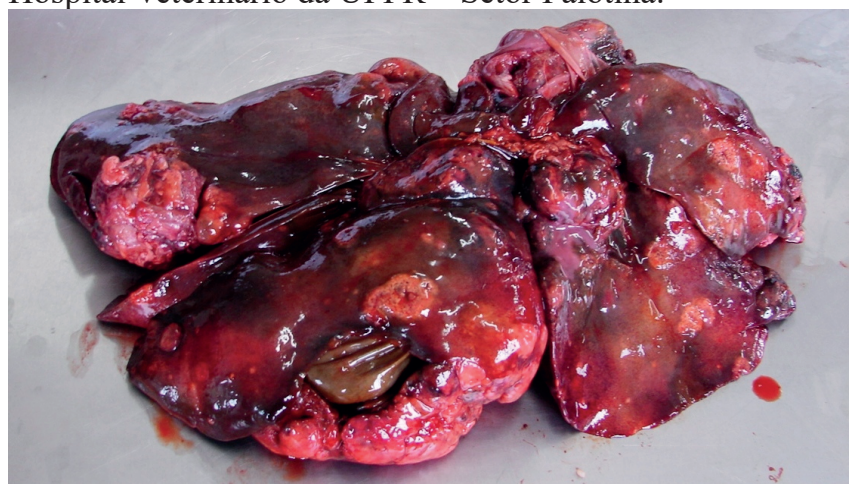

Figura 2: Nódulos de metástase multifocais em omento de um cão macho, SRD, submetido à necropsia no Laboratório de Patologia do Hospital Veterinário da UFPR - Setor Palotina.

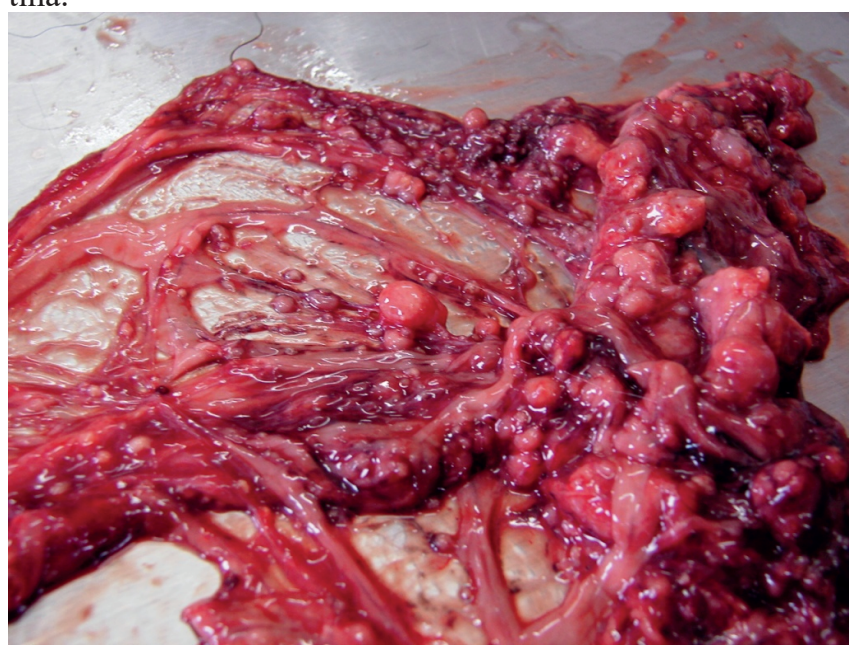

Os órgãos foram colhidos, fixados em formol a $10 \%$, processados pela técnica de impregnação em parafina e corados pela Hematoxilina-Eosina (H.E).

Ao exame histopatológico das massas localizadas no fígado foram observadas células epiteliais pleomórficas com pigmento marrom intracitoplasmático, organizadas em arranjo tubular e separadas por estroma de tecido conjuntivo (Figura 3), havendo ainda algumas áreas de necrose com calcificação das células neoplásicas. Os nódulos presentes no omento correspondiam à metástase, que ocorreu também para os linfonodos hepáticos e pancreáticos e formação de êmbolos tumorais obstruindo os vasos do estroma pancreático. 
Figura 3: Aspecto microscópico do colangiocarcinoma com arranjo tubular (HE. Aumento 40X) de cão macho, SRD, submetido à necropsia no Laboratório de Patologia do Hospital Veterinário da UFPR - Setor Palotina

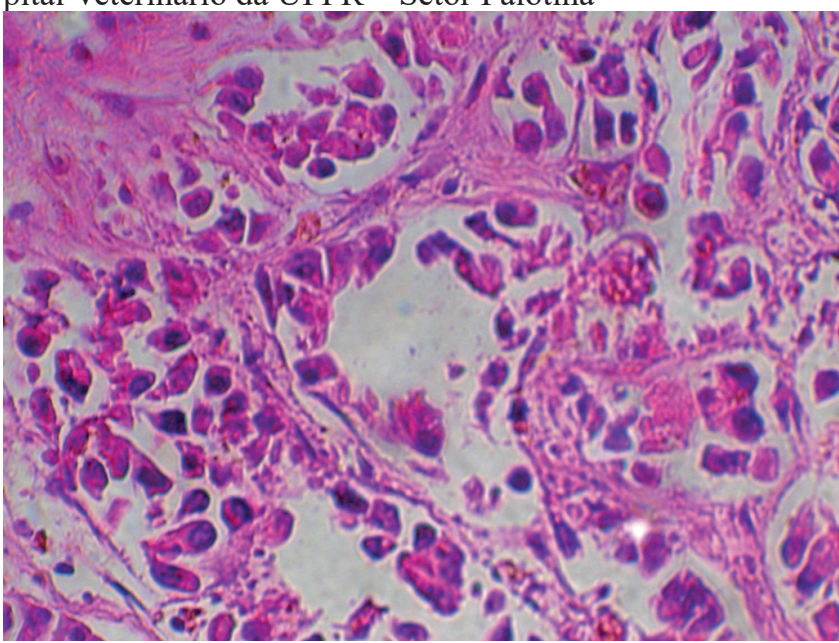

\section{Discussão}

Alguns dos sinais clínicos e alterações bioquímicas mais comumente descritos na literatura foram observados neste caso clínico (CULLEN; POPP, 2002) e embora a icterícia não tenha sido mencionada no histórico clínico do animal, foi observada ao exame externo durante a necropsia. $\mathrm{O}$ achado de líquido na cavidade abdominal é comum (ECHETO et al., 2005; CULLEN; POPP, 2002) e ocorre em doenças hepáticas crônicas com fibrose devido a hipertensão portal e hipoproteinemia (MACLACHLAN; CULLEN, 1998).

$\mathrm{O}$ aspecto macroscópico umbilicado dos nódulos hepáticos de cor branca amarelada e consistência firme é concordante com a descrição macroscópica da literatura para colangiocarcinoma, sendo importante para descartar o principal diagnóstico diferencial que é o hepatocarcinoma. Esse pode se apresentar com padrão massivo, envolvendo um único lobo hepático; padrão nodular, com múltiplos nódulos ou difuso, caracterizado por pequenas massas indistintas por meio do parênquima (CULLEN; POPP, 2002).

A presença de células neoplásicas pleomórficas que relembram os ductos biliares e se organizam em um arranjo tubular ou acinar caracterizam o neoplasma como colangiocarcinoma (ECHETO et al., 2005; CULLEN; POPP, 2002). A presença da extensa quantidade de estroma conjuntivo constitui um dos parâmetros importantes para diferenciar o colangiocarcinoma do carcinoma hepatocelular do tipo adenoide que tem estroma em pequena quantidade ou ausente (TRIGO et al., 1982). O acúmulo intraluminal de mucina nas estruturas tubulares das neoplasias de ductos é demonstrado pela coloração de Alcian Blue, sendo também considerado mais um parâmetro diferencial (SHIGA et al., 2001). Este procedimento não foi realizado neste caso.

Além desses parâmetros morfológicos, a distinção entre os carcinomas hepatocelulares e os colangiocarcinomas pode ser facilitada pelo uso de anticorpos como a citoceratina - 7 (CK7) usados para detectar tumores de origem biliar (MISCHKE, 2003; RAMOS-VARA et al., 2001). Em experimentos realizados com CK7, ela foi detectada em todos os neoplasmas benignos e lesões biliares hiperplásicas e em mais de $75 \%$ dos colangiocarcinomas (RAMOS-VARA et al., 2001).

O hepatocarcinoma celular de padrão pseudoglandular não deve ser confundido com a forma combinada de colangiocarcinoma e hepatocarcinoma, que é um neoplasma raro descrito em humanos, cães e equinos, que compartilha as características morfológicas e imunohistoquímicas dos dois neoplasmas (SHIGA et al., 2001; KATO et al., 1997). Neoplasmas malignos de origem pancreática quando fazem metástase para o fígado também podem ser confundidos com carcinoma de ductos biliares (KELLY, 1993).

Neoplasmas malignos dos ductos biliares têm um padrão altamente invasivo de crescimento e fazem metástases com grande frequência, sendo a taxa de metástase extra-hepática em cães em torno de 60 a 88\% (CULLEN; POPP, 2002). Neste caso aparentemente foi verificado disseminação do neoplasma por todas as vias, inclusive com a presença de trombos com células neoplásicas em vasos do pâncreas, similar a metástase pancreática e disseminação para linfonodos regionais descritas por Trigo et al. (1982). A literatura também cita a ocorrência de metástase em outros órgãos como pulmões, rins, baço, osso, diafragma, pâncreas, adrenais, coração, outros linfonodos e o peritônio (TRIGO et al., 1982), estômago, mediastino, tiroide, cerebelo e medula óssea (MISCHKE, 2003). Neste caso foi encontrado metástase apenas em omento, linfonodos regionais e pâncreas.

\section{Conclusão}

A partir dos achados macroscópicos e microscópicos o diagnóstico foi firmado como colangiocarcinoma dos ductos biliares com metástases para omento, linfonodos regionais (hepáticos e pancreáticos) e pâncreas, sugerindo a ocorrência de disseminação neoplásica por via hematógena, linfática e por implantação.

\section{Referências}

BONFANTI, U. et al. Percutaneous fine-needle biopsy of deep thoracic and abdominal masses in dogs and cats. Journal of Small Animal Practice, v. 45, p. 191-198, 2004.

CULLEN, J. M.; POPP, J. A. Tumors of the liver and gall bladder. In: MEUTEN, D. J. (Ed.). Tumors in domestic animals. 4. ed. California: Iowa State Press, 2002. p. 483508 .

ECHETO, O. E. V. et al. Peritonitis infecciosa felina, gastroenteritis y colangiohepatitis parasitaria (platinosomiasis) con colangiocarcinoma hepático: estudo clínico y anatomopatológico de tres casos. Revista

Cientifica Facultad de Ciencias Veterinarias de la Universidad del Zulia, v. 15, p. 195-203, 2005.

\section{KANEKO, J. J. Clinical biochemistry of domestic} animals. 4. ed. London: Academic Press, 1989. 932 p.

KATO, M. et al. Combined hepatocellular carcinoma and cholangiocarcinoma in a mare. Journal of Comparative Pathology, v. 116, p. 409-413, 1997. 
KELLY, W. R. The liver and biliar system. In: JUBB, K. V. F.; KENNEDY, P. C.; PALMER, N. Pathology of domestic animals. 4. ed. San Diego: Academic Press, 1993. p. 319406.

MACLACHLAN, N. J.; CULLEN, J. M. Fígado, sistema biliar e pâncreas exócrino. In: CARLTON, W. W.;

MCGAVIN, M. D. Patologia veterinária especial de Thomson. 2. ed. Porto Alegre: Artmed, 1998. p. 95-131.

MISCHKE, R. et al. Immunocytological confirmation of bone marrow metastases in a dog with cholangiocarcinoma. Journal of small animal practice, v. 44, p. 411-414, 2003.

PATNAIK, A. K. et al. Canine bile duct carcinoma. Veterinary Pathology, n. 18, p. 439-444, 1981.

RAMOS-VARA, J. A.; MILLER, M. A.; JOHNSON, G. C. Immunohistochemical characterization of canine hyperplastic hepatic lesions and hepatocellular and biliary neoplasms with monoclonal antibody hepatocyte paraffin 1 and a monoclonal antibody to cytokeratin 7 . Veterinary Pathology, v. 38, p. 636-643, 2001.

SHIGA, A.; SHIROTA, K.; ENOMOTO, M. Combined hepatocellular and cholangiocellular carcinoma in a dog. Journal of Veterinary Medical Science, v. 63, n. 4, p. 483486, 2001.

TAYLOR, G. N. et al. Plutonium-or americium-induced liver tumors and lesions in beagles. Health Physics, v. 61, n. 3 , p. 337-47, 1991.

TRIGO, F. G. et al. The pathology of liver tumours in the dog. Journal of Comparative Pathology, v. 92, p. 21-39, 1982. 